\title{
Tapia Syndrome after Cervical Spine Surgery
}

\author{
Jung Hoon Kang', Dong Min Kim², Seok Won $\mathrm{Kim}^{3}$ \\ Departments of Rehabilitation ${ }^{1}$, Internal Medicine ${ }^{2}$, Neurosurgery ${ }^{3}$, Chosun University College of Medicine, Gwangju, Korea
}

Tapia syndrome is a rare entity characterized by unilateral paralysis of the tongue and vocal cord caused by $\mathrm{X}^{\text {th }}$ and $\mathrm{X} \mathrm{II}^{\text {th }}$ cranial nerve lesions. However, there has been no report of Tapia syndrome immediately following spine surgery. A 47year-old man underwent posterior decompressive laminectomy for cervical stenosis. The surgery took about 117 minutes and it was uneventful. Postoperatively he developed hoarseness of voice during speech, with deviation of tongue protrusion. On laryngoscopic examination, paralysis of the left side of the tongue and the soft palate was found and complete palsy of the left vocal cord was noted. After excluding surgical cause and craniocervical lesion, a clinical diagnosis of Tapia syndrome was made. Here we report a rare case of Tapia syndrome developed after posterior approach for cervical spine surgery and discuss the possible mechanisms of this uncommon syndrome.

Key Words: Cranial nerve palsy $\cdot$ Tapia syndrome $\cdot$ Spine surgery

\section{INTRODUCTION}

Tapia syndrome is characterized by unilateral paralysis of the tongue and vocal cord caused by lesions of the $\mathrm{X}^{\text {th }}$ and $\mathrm{XII}^{\text {th }}$ cranial nerves. The most common clinical symptoms are hoarseness, dysphagia and difficulty in tongue movement ${ }^{1)}$. The main causes of Tapia syndrome are parotid tumors and other lesions or injuries to the upper neck ${ }^{9}$. . Here we report a patient who immediately developed unilateral paralysis of the tongue and vocal cord following decompressive laminectomy at $\mathrm{C} 3$ to $\mathrm{C} 6$.

\section{CASE REPORT}

A 47 year old male was admitted to the spine center due to arm tingling sensation and pain, bilaterally. Cervical magnetic resonance imaging (MRI) revealed significant stenosis at the $\mathrm{C} 3$ to $\mathrm{C} 6$ levels. The laboratory findings including coagu-

- Received: September 26, 2013 • Revised: November 4, 2013

- Accepted: November 7, 2013

Corresponding Author: Seok Won Kim, MD, PhD

Department of Neurosurgery, School of Medicine, Chosun University, 365

Pilmun-daero, Dong-gu, Gwangju-city 501-717, Korea

Tel: +82-62-220-3126, Fax: +82-62-227-4575

E-mail: ns64902@hanmail.net/chosunns@chosun.ac.kr

"This study was supported by reseurch funds from Chosun University 2013.

@This is an Open Access article distributed under the terms of the Creative

Commons Attribution Non-Commercial License (http://creativecommons.org/

licenses/by-nc/3.0/) which permits unrestricted non-commercial use, distribution,

and reproduction in any medium, provided the original work is properly cited. lation testing prior to the surgery were within normal limits. Intramuscular injection of midazolam $2.5 \mathrm{mg}$ was provided for premedication. Induction of anesthesia was achieved with an initial target controlled plasma level of $3.5 \mathrm{ug} / \mathrm{mL}$ of propofol, and infusion of $0.1 \mathrm{ug} / \mathrm{kg} / \mathrm{min}$ of remifentanil. Neuromuscular blockade was achieved with rocuronium $0.6 \mathrm{mg} / \mathrm{kg}$. After 2 minutes, transoral intubation by direct laryngoscopy was performed gently. A size 8 endotracheal tube was inserted and then secured to prevent dislodgement or loosening, at a left angle to the mouth. In addition, cuff inflation was performed using $4 \mathrm{~mL}$ of room air. After endotracheal intubation, mechanical ventilation was adjusted to maintain normocarbia, using $1 \mathrm{~L} / \mathrm{min}$ of $\mathrm{O}_{2}$ and $2 \mathrm{~L} / \mathrm{min}$ of medical air. The patient was turned prone on the operating table, keeping the neck in line with the spine. The head was kept in a hyperflexion position using Mayfield head pins for better surgical view. To keep the neck in flexion, the chin was tried to be sutured to the anterior chest. Anesthesia was maintained with a propofol plasma target between 3.0 and $3.5 \mathrm{ug} / \mathrm{mL}$ and the remifentanil infusion between 0.05 and $0.1 \mathrm{ug} / \mathrm{kg} / \mathrm{min}$. The surgery lasted $117 \mathrm{~min}$. Decompressive laminectomy at the C3 to C6 levels by the posterior approach was performed. The surgery was uneventful. At completion of surgery, the propofol and remifentanil infusions were discontinued, a reversal agent was administered intravenously, and spontaneous respirations returned after 9 minutes, at which time the endotracheal tube was removed. The patient was transferred to the recovery room and was alert and oriented within five minutes of leaving the operating room. After extubation, the patient complained of throat and neck pain with hoarseness. Forty eight 


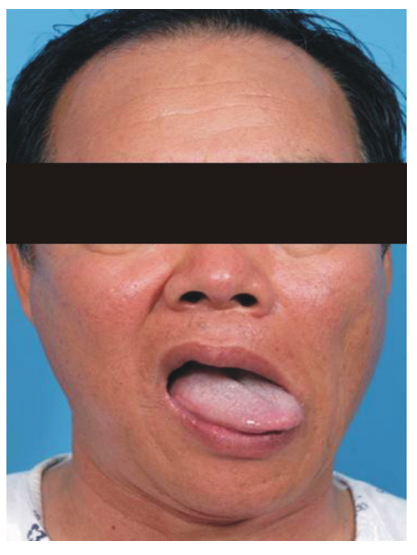

Fig. 1. This picture shows the tongue deviation to the left side during tongue protrusion.

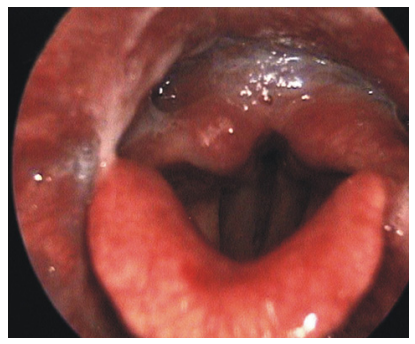

Fig. 2. Laryngoscopic finding shows complete palsy of left vocal cord.

hours later, these symptoms persisted, and were associated with dysphagia. On laryngoscopic examination, paralysis of the left side of the tongue and the soft palate was found and complete palsy of the left vocal cord was noted (Fig. 1, 2). The remainder of the neurological examination was normal. Horner's syndrome was not present. The next day, vertebral and carotid ultrasonography, cerebral computed tomography, magnetic resonance imaging, and magnetic resonance angiography of the brain and neck were carried out. The results were normal with no ischemia, abscess formation, tumor, or hemorrhage found. Corticosteroid therapy was provided for two weeks and speech therapy, by the rehabilitation department, was started. Two weeks later, the patient started to recover to some degree; however, the symptoms were still present at eight months after operation.

\section{DISCUSSION}

Extracranial involvement of the recurrent laryngeal nerve and the hypoglossal nerve is known as Tapia syndrome ${ }^{1-3,}$. Our patient developed this combination of abnormalities immediately after decompressive laminectomy performed by the posterior approach. The combination injury of the hypoglossal and vagal nerves due to extracranial involvement is very rare. The vagal nerve leaves the cranium through the jugular foramen and passes through the neck to the thorax. The $9^{\text {th }}$, $10^{\text {th }}$ and $11^{\text {th }}$ cranial nerves are anterior to the internal jugular

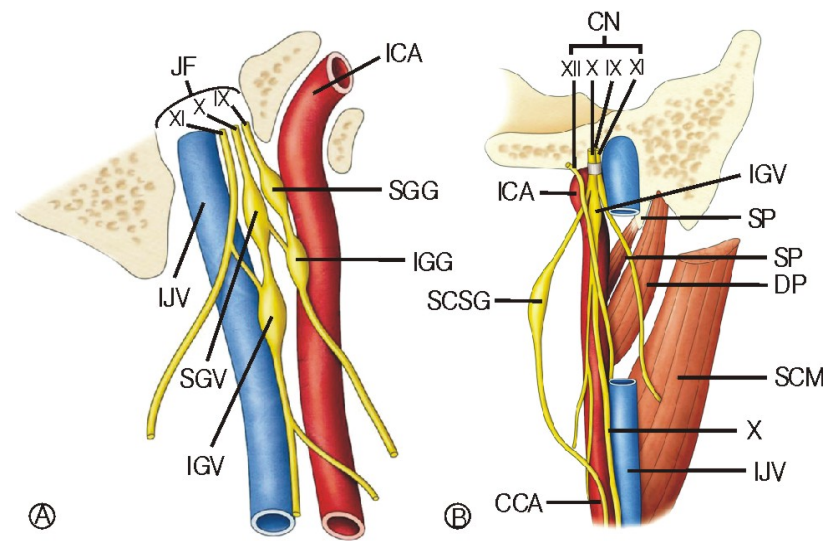

Fig. 3. Schematic pictures of the jugular foramen region show the relationship of structures. $A$ : Cranial nerve $I X, X$, and $X I$ are anterior to the IJV as they traverse the jugular foramen. $B$ : The hypoglossal nerve descends and crosses the vagal nerve in order to continue to its route medially.

DP: Digastric posterior belly, IX: Golssopharyngeal nerve

$X$ : Vagus nerve, $\mathrm{XI}$ : Spinal accessory nerve

ICA: Internal carotid artery,

IGG: Inferior ganglion of glossopharyngeal nerve,

IJV: Internal jugular vein, JF: Jugular Foramen,

SGV: Superior gangion of vagus nerve,

SGG: Superior gangion of glossopharyngeal nerve,

IGV: Inferior ganglion of vagus nerve,

SP: Styloid process, SP: Stylopharyngeus,

SCM: Sternocleidomastoid, SCSG: Superior cervical sympathetic ganglion, CCA: Common carotid artery

vein (IJV) as they traverse the jugular foramen. They are immediately posterior to the internal carotid artery (ICA) as they emerge from it. The superior and inferior sensory ganglion of the $9^{\text {th }}$ and $10^{\text {th }}$ nerve are seen as thickening immediately inferior to their exit from the cranium (Fig. 3A). The hypoglossal nerve is medial to the $9^{\text {th }}, 10^{\text {th }}$ and $11^{\text {th }}$ cranial nerves after they exit the cranium through the hypoglossal canal. The hypoglossal nerve descends to the anterior cervical region; along this path it is near to the surface of the inferior vagal ganglion (Fig. 3B). Then the hypoglossal nerve crosses the vagal nerve in order to continue its route medially and ultimately reaches the tongue and supply all the extrinsic muscle of the tongue ${ }^{5}$. This close relationship between the vagal and hypoglossal nerve explains why both nerves can be injured simultaneously ${ }^{2,3,6,9)}$. The main causes of Tapia syndrome are tumors or injury to the upper neck as well as congenital and idiopathic lesions including iatrogenic causes such as endotracheal intubation ${ }^{7-9)}$. There are recent reports in the literature on Tapia syndrome after oro-tracheal intubation resulted from compression by the cuff pressure of the endotracheal tube and prolonged stretching of cranial nerves by improper 
positioning of the head ${ }^{9}$. Namely, poor and inadequate body position during surgery may cause the Tapia syndrome. Boisseau et al. reported the Tapia syndrome following shoulder surgery caused by fully upright sitting position ${ }^{2}$. He presumed cranial nerve injuries could occur due to compression by the tracheal tube resulted from excessive displacement of the head. Moreover, the endotracheal tube might have caused symptoms in this patient such as disturbance of laryngeal function and swallowing. In our patient, transoral intubation was performed without any problem, the pressure was checked regularly, and nitrous oxide was not given. In fact, we do not know exact etiology of these cranial nerves paralysis. However, we speculate the involved possible mechanisms include compression of nerves against the mandible by excessive anterior flexion of neck or stretching of the cranial nerves by the tracheal tube itself or the cuff pressure in spite of regular pressure check $^{3)}$. So, we believe that although neck flexion is necessary for posterior prone position, we would recommend avoidance of excessive prolonged hyperflexion of the neck and adequate cuff pressure during surgery. Although steroids are most commonly used to treat these cranial nerve palsies, there is no definitive therapy. In some cases, administration of steroids and vitamins may be used to shorten the recovery period ${ }^{4,7}$. We followed our patient for eight months but the symptoms were not improved despite conventional steroid therapy.

\section{CONCLUSION}

We report a rare case of immediately developed Tapia's syndrome following cervical spine surgery by posterior approach. Although it is rare and unpredictable, the possibility of unintended cranial nerve injuries should be kept in mind after cervical spine surgery.

\section{REFERENCES}

1. Andrioli G, Rigobello L, Mingrino S, Toso V: Tapia's syndrome caused by a neurofibroma of the hypoglossal and vagus nerves: case report. J Neurosurg 52:730-732, 1980

2. Boisseau N, Rabarijaona H, Grimaud D, Raucoules-Aim? M: Tapia's syndrome following shoulder surgery. $\mathrm{Br} \mathrm{J}$ Anaesth 88: 869-870, 2002

3. Gelmers HJ: Tapia's syndrome after thoracotomy. Arch Otolaryngol 9:622-623, 1983

4. Keane JR: Twelfth nerve palsy: Analysis of 100 cases. Arch Neurol 53:561-566, 1996

5. Keith L. Moore, Arthur F. Dalley, Anne MR. Agur: Clinically Oriented Anatomy Sixth Edition. United states of America: Lipp- incott Williams \& Wilkins, 2009, pp1035-1036 \& 1074

6. Ma HJ, Kim IS: Horner syndrome associated with a herniated cervical disc: A case report. Korean J Spine 9(2):108-110, 2012

7. Millan Guevara J, Royo Lopez J, Pascual Millan LF, Rivas Rodriguez P, Fumanal Senz L, Castellote Armero A: Idiopathic associated paralysis of the $\mathrm{X}^{\text {th }}$ and XII ${ }^{\text {th }}$ cranial nerves. An Otorrinolaringol Ibero Am 20:61-64, 1993

8. Ruhrmann G: Congenital right-sided vagus and hypoglossal nerve paralysis (Tapia syndrome) as the cause of congenital stridor. Z Kinderheilkd 88:22-26, 1963

9. Yavuzer R, Basterzi Y, Özköse Z, Demir HY, Ylmaz M, Ceylan A: Tapia syndrome following septorhinoplasty. Aesth Plast Surg 28:208-211, 2004 